\title{
Multi-objective method for divisible load scheduling in multi-level tree network
}

\begin{abstract}
There is extensive literature concerning the divisible load theory. Based on the divisible load theory (DLT) the load can be divided into some arbitrary independent parts, in which each part can be processed independently by a processor. The divisible load theory has also been examined on the processors that cheat the algorithm, i.e., the processors do not report their true computation rates. According to the literature, if the processors do not report their true computation rates, the divisible load scheduling model fails to achieve its optimal performance. This paper focuses on the divisible load scheduling, where the processors cheat the algorithm. In this paper, a multi-objective method for divisible load scheduling is proposed. The goal is to improve the performance of the divisible load scheduling when the processors cheat the algorithm. The proposed method has been examined on several function approximation problems. The experimental results indicate the proposed method has approximately $66 \%$ decrease in finish time in the best case.
\end{abstract}

Keyword: Divisible load theory; Multi-objective method; Multi-level tree network; Divisible load scheduling 